\title{
THE CHEMISTRY OF DAYLIGHT VISION
}

\author{
BY ALFRED' FREDERICK BLISS \\ (From the Laboratory of Biophysics, Columbia University, New York)
}

(Received for publication, February 7, 1946)

\section{Photopic and Scotopic Vision}

Daylight vision in man is synonymous with color vision, a faculty which is equally prominent in diurnal fish, reptiles, and birds. Mammals other than the primates seem to be color blind and yet may possess the same types of visual cells as color discriminating forms. Color vision thus represents one aspect of a broader system known as daylight or photopic vision. This system, which is functional only at the relatively high intensities of ordinary daylight, is characterized by the high.visual acuity it affords and by a spectral visibility curve maximal at $555 \mathrm{~m} \mu$ in the yellow green (Ives, 1912; Hyde, Forsythe, and Cady, 1918; Coblentz and Emerson, 1917; Gibson and Tyndall, 1923; Stiles, 1944; Pinegin, 1944; and Wald, 1945).

The visibility curve may be defined as the reciprocal of the energy or, more usefully, of the number of quanta required to produce a constant brightness throughout the spectrum. The determination of this curve is complicated by the fact that color differences confuse the estimation of brightness. This difficulty has been minimized by matching adjacent regions of the spectrum step by step (Gibson and Tyndall) or by flicker photometry (Coblentz and Emerson), a method in which advantage is taken of the fact that alternate presentation of two colors at a sufficiently high frequency results in fusion of the colors without disappearance of the flicker due to the difference in their brightness.

If the intensity of spectral light is lowered enough a region is entered in which the light appears colorless. In this range a visibility curve with a maximum about $500 \mathrm{~m} \mu$ in the blue-green is obtained (Hecht and Williams, 1922). Clearly a different, color blind, system is functioning at these low energies. Known as the scotopic system, it has furnished nearly all our knowledge of the chemistry of visual substances.

\section{The Chemistry of Scotopic Vision}

The scattered and often contradictory observations on the chemistry of daylight vision require confirmation and extension. Since the kinetic data of vision show a close relation between scotopic and photopic vision in such features' as light and dark adaptation, visual acuity, and intensity discrimination (Hecht, 1937), a summary of the salient features of the scotopic system will serve as a useful introduction to this investigation. More detailed in- 
formation may be obtained from the recent reviews by Hecht (1942) and Wald (1943).

Scotopic vision is correlated with the presence of large numbers of rod cells in the retina. The rod-rich retinas of the frog were found by Boll in $\mathbf{1 8 7 6}$ to contain a red substance which bleaches in the light and reforms in the dark. This substance, known as visual purple or rhodopsin, may be extracted into aqueous solution by surface-active detergents such as the bile salts (Kühne, 1877), digitonin and saponin (Tansley, 1931). The absorption spectrum of purified visual purple (Chase and Haig, 1938; Lythgoe, 1937; Wald, 1938;

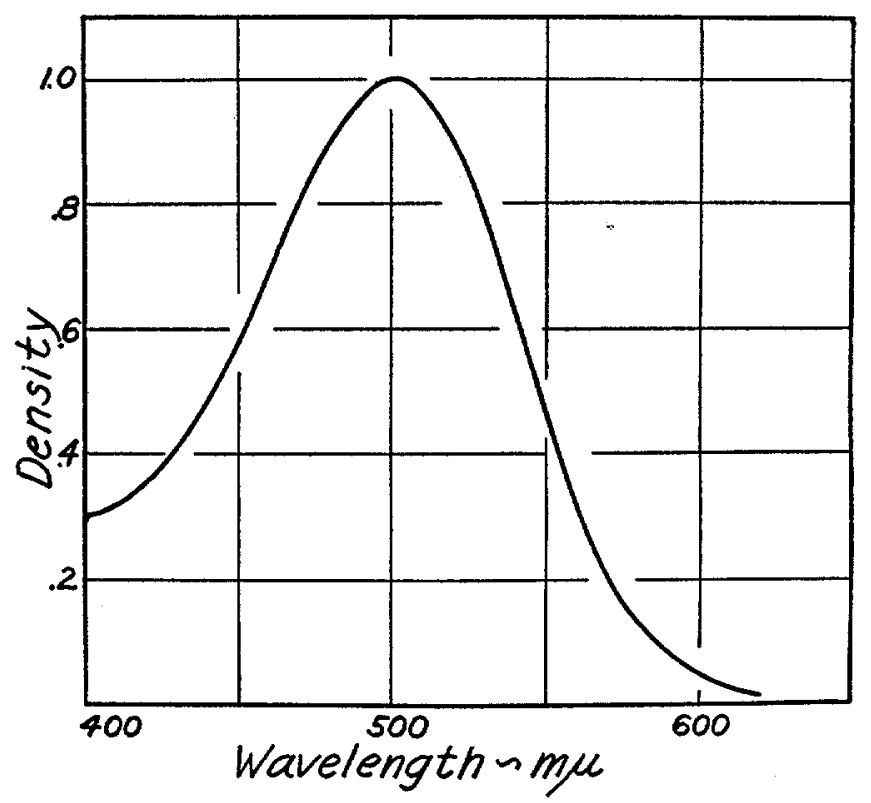

FIg. 1. Absorption spectrum of visual purple (Hecht, 1942). Average of data from three sources (Chase and Haig, 1938; Wald, 1938; and Lythgoe, 1937).

and Krause and Sidwell, 1938) forms an unsymmetric curve with a maximum at $500 \mathrm{~m} \mu$. The absorption spectrum of frog's rhodopsin, collected from three sources, is shown in Fig. 1.

Exposure to light results in a fall in absorption maximal at $510 \mathrm{~m} \mu$ and a rise in absorption toward the violet end of the spectrum. The difference spectrum of visual purple is shown in Fig. 2, B. The rise in absorption in the blue means that rhodopsin bleaches to a yellow photoproduct. The difference spectrum is therefore only approximately similar to the absorption spectrum.

When the scotopic visibility curve is computed as the relative number of 
quanta which must reach the retina in order to evoke a given visual sensation (Schneider, Goodeve, and Lythgoe, 1939) good agreement is found with the absorption of the same amount of rhodopsin known to be in the human retina (Wald, 1938; Hecht, Shlaer, and Pirenne, 1942). All these facts demonstrate that rhodopsin is the basis of scotopic vision.

Rhodopsin has the physical and chemical properties of a protein. It is destroyed by heat above $50^{\circ} \mathrm{C}$., strong acid or base, and by many polar organic solvents. If an excised retina is illuminated just long enough to bleach it and is then shaken with chloroform, a yellow carotenoid, retinene, is extracted (Wald, 1935). This previously unknown pigment is characterized by an absorption peak at $387 \mathrm{~m} \mu$ in chloroform and at $664 \mathrm{~m} \mu$ with antimony trichloride. Since oxidation of vitamin A produces a similar chromogen (Hunter and Hawkins, 1944) Morton and Goodwin (1944) suggest that retinene is vitamin A aldehyde. After prolonged illumination retinene can no longer be found. In its place however is a substance absorbing maximally at $328 \mathrm{~m} \mu$ with the properties of vitamin A. Rhodopsin therefore appears to be a conjugated protein which liberates a prosthetic group related to vitamin $\mathrm{A}$ as a consequence to the absorption of light.

Dark adaptation of the living eye results in the removal of vitamin A and the regeneration of visual purple. Deficiency of vitamin A in the diet results in night blindness due to the failure of visual purple regeneration (Holm, 1925; Fridericia and Holm, 1925; Tansley, 1931). It is significant that the photopic threshold also rises in this condition (Hecht and Mandelbaum, 1938), suggesting that photopic vision likewise involves vitamin A.

\section{Cone Pigments}

The similarity in the dynamics of the photopic and scotopic systems leads us to look for rhodopsin-like pigments basic to photopic vision. Daylight vision is correlated with the presence in the retina of large numbers of cone cells. These are somewhat similar to the rods but contain no visible photosensitive pigments. Köttgen and Abelsdorff (1896) made glycocholate extracts of the pure cone retinas of tortoises, and Kühne (1877) investigated the chicken retina but in neither animal could any trace of photopigment be demonstrated. The fact that the energy threshold for photopic vision is about 100 times the scotopic level in human beings suggests that one reason for the failures was the low concentration of cone substances. It has therefore become clear that further progress requires the application of high precision spectrophotometric methods to the cone-rich retinas of the diurnal birds, reptiles, or mammals.

In recent years several investigators have reported the extraction of cone pigments from tortoises, chickens, and frogs. The first claim was made by von Studnitz (1937) who reported that ether extracts of tortoise and frog 
retinas contained a photosensitive substance with a maximum absorption at $570 \mathrm{~m} \mu$. However, this claim cannot be accepted because the height of this absorption maximum is little greater than the sensitivity of his galvanometer ( $1 \mathrm{~mm}$. deflection for $0.1 \mathrm{lux}$ ). In his figure of the absorption spectrum of cone substance from frogs the absorption peak at $570 \mathrm{~m} \mu$ absorbs 0.3 per cent more light than the minimum on the long wave side. Since the total illumination is 4.5 lux, a difference in absorption of 0.3 per cent would cause the scarcely detectable change in deflection of only $0.14 \mathrm{~mm}$. The insignificance of this peak is further emphasized by the fact that von Studnitz ignores the existence of an absorption at $630 \mathrm{~m} \mu$ actually greater than that at $570 \mathrm{~m} \mu$.

So much has been made of these findings by von Studnitz (1940) that the experiments seemed worthy of repetition even though Hosoya, Okita, and Akune (1938) and Wald (1943) have already failed to confirm them. An ether extract of frog retinas was prepared following the procedure in his report and was measured on Shlaer's spectrophotometer (1937). The solution yielded only a smooth absorption curve rising into the violet, and showed no photosensitivity.

Hosoya, Okita, and Akune (1938) presented evidence for cone pigments of more conventional properties in saponin and glycocholate extracts of tortoise and frog retinas. They reported difference spectra with several poorly defined peaks supposedly representing bleaching of the cone primary substances by their measuring light source.

In the course of a search for cone substance in the frog, I found a similar fall in the absorption of freshly prepared extracts quite independent of illumination. This fall apparently is due to autolysis of the fresh extract. Since Hosoya and his coworkers present no control data in this regard, their results are open to question.

Wald (1937) reported the extraction of a photosensitive cone pigment from chicken retinas with aqueous digitalin. Since a small quantity of rhodopsin is present in the eyes of chickens he found it necessary to bleach the solution with dim red light beyond $650 \mathrm{~m} \mu$, to which rhodopsin is relatively insensitive. Exposure to red resulted in a decided drop in absorption maximal at $570 \mathrm{~m} \mu$ in the yellow, and a rise beginning at about $460 \mathrm{~m} \mu$ and extending into the ultraviolet. Evidently the chicken retinas contained an extractable redsensitive substance which bleached to form a yellow photoproduct. Wald has proposed the name "iodopsin" for this new visual pigment. It is significant that its difference absorption spectrum bears a rough resemblance to the visibility curve of the light-adapted chicken (Honigman, 1921).

After the idodopsin was completely bleached exposure to white light resulted in a further fall in absorption with a maximum at $510 \mathrm{~m} \mu$ characteristic of visual purple.

I have been able to reproduce Wald's results in a great many repetitions of 
his work. A typical set of curves obtained from an extract prepared as described below may be seen in Fig. 2. While the heights of the difference spectra in this figure have been arbitrarily adjusted to the same height, actually the maximum density fall resulting from the bleaching of iodopsin was found usually to be about $\frac{3}{4}$ that of rhodopsin.

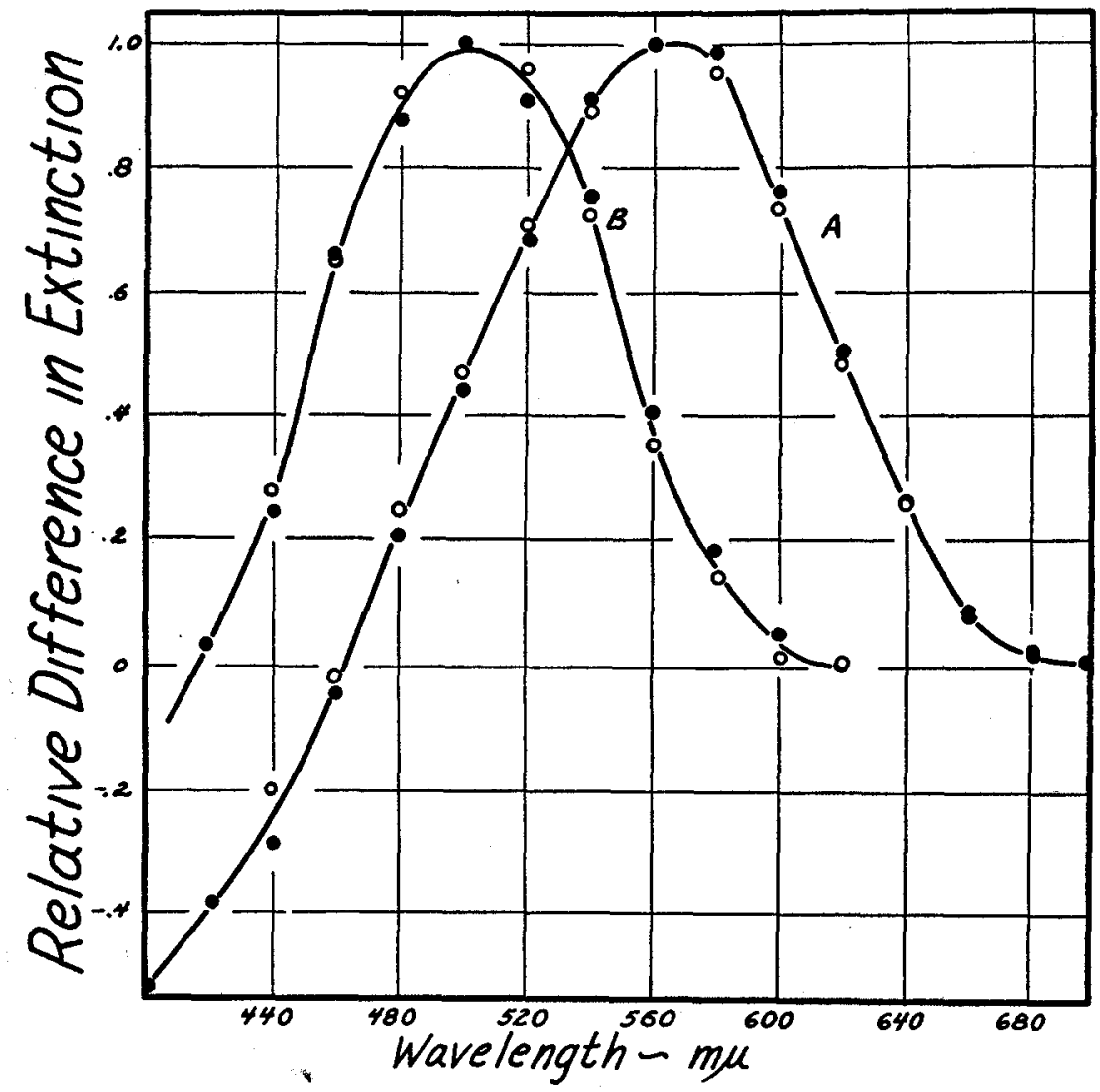

Fic. 2. Difference absorption spectra of photosensitive pigments from chicken eyes. A, change due to red light. B, change due to white light after completion of bleaching by red light.

Wald's discovery is a significant start toward a chemistry of cone vision. It was therefore decided to obtain further information about the photochemical properties of iodopsin.

\section{Apparatus}

The instrument with which most of this investigation has been carried out is a potentiometric photoelectric spectrophotometer (Bliss, 1943). Its main features are shown in Fig. 3. 
The light of a 32 c.p. 6 volt storage battery-operated automobile headlight bulb is passed through a prism monochromator with a range of 360 to $700 \mathrm{~m} \mu$. The wavelength scale is calibrated with mercury and helium spectra and may be read to the nearest millimicron. The bilateral slits are adjusted to produce an approximately equal sensitivity through the spectrum. Under these conditions the band width varies between 5 and $10 \mathrm{~m} \mu$.

The solution to be measured is contained in a $1 \mathrm{~cm}$. corex $\mathrm{D}$ cell of $1 \mathrm{cc}$. volume which is mounted on a shuttle in a removable light-tight box. The solution may be moved in and out of the beam, permitting measurement of the transmission $\left(I_{t r} / I_{o}\right)$. When the shuttle is pushed to the far end of the box, light is admitted for tests of photosensitivity.

Stray light, always a source of error when making density measurements in regions of low energy, could be disregarded above $400 \mathrm{~m} \mu$ due to the use of a RCA 926 photo-

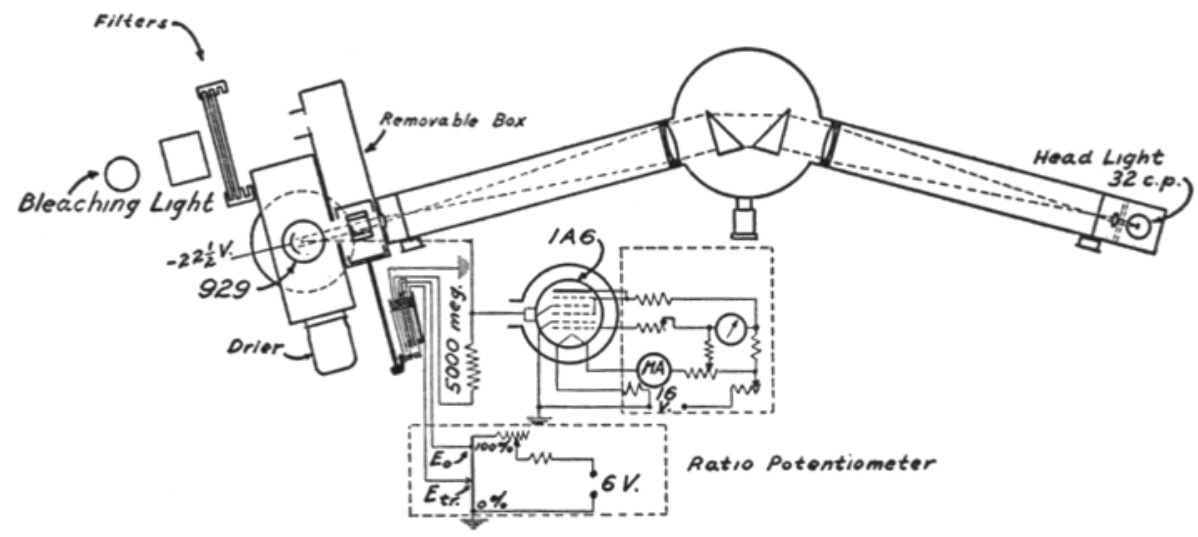

FIG. 3. Plan of spectrophotometer and bleaching lights.

tube with maximum sensitivity in the blue. At present even better response in the blue is attained with the use of a 929 tube with maximum sensitivity at $375 \mathrm{~m} \mu$. The anode lead of this tube is passed through a hole provided by the removal of the center post of the tube base, to reduce insulation leakage. The small energy in the ultraviolet spectrum of the source necessitates the use of a Corning 597 filter in front of the monochromator to cut down stray light of longer wavelengths when measuring densities below $400 \mathrm{~m} \mu$.

The photoelectric amplifier used for this investigation consisted of a $1 \mathrm{A6}$ tube in Barth's modification (Penick, 1935) of a DuBridge and Brown balanced circuit. However, much greater gain and stability is now achieved with a twin triode 6F8, in a bridge circuit. The grid leak consists of a 300 megohm India ink line resistor. A box galvanometer with a sensitivity of $30 \mathrm{~mm}$. per $\mu \mathrm{a}$ is used as a null point indicator with an 11 turn helical potentiometer giving the transmission $\left(I_{t r} / I_{0}\right)$ directly. Results usually are expressed as photometric density ( $-\log$ transmission). 


\section{Efforts at Purification of Iodopsin}

(a) Stability.-The following observations show that iodopsin bears considerable resemblance to rhodopsin but is much more labile. Unless otherwise noted 4 to 12 retinas per ml. were extracted in 2 per cent digitalin for 4 to 8 hours.

While rhodopsin may be extracted after exposure of the retinas to 4 per cent alum at a pH of 2.9 and is unharmed in solution at $\mathrm{pH} 10$, iodopsin could not be extracted if the retinas were previously soaked for 1 hour in $0.1 \mathrm{M}$ acetate buffer below pH 4.4. Full yield was not obtained below pH 4.9. Extraction at $\mathrm{pH} 8.5$ yielded only a trace of iodopsin. Unbuffered extracts kept for 2 weeks at $5^{\circ} \mathrm{C}$. yielded the difference spectrum of rhodopsin alone.

Iodopsin could not be extracted by 4 per cent sodium glycocholate or salicin and was destroyed in about 2 hours at room temperature by addition of an equal amount of 4 per cent sodium desoxycholate to a 2 per cent digitalin extract. It is significant that most of the earlier workers used sodium glycocholate in their unsuccessful attempts to extract iodopsin.

Whereas rhodopsin is precipitated unbleached by the addition of formalin to make a concentration of 10 per cent or by the addition of an equal amount of acetone in the cold, iodopsin is destroyed under the same conditions.

As in the case of rhodopsin it proved possible to dry iodopsin in vacuo at $0^{\circ}$ and to redissolve it largely without destruction by grinding with sand in 2 per cent digitalin.

Both iodopsin and rhodopsin could be extracted from retinas hardened by soaking in 25 per cent saturated lead acetate followed by rinsing with Ringer's solution. No iodopsin could be extracted when fully saturated lead acetate was used.

(b) Purification.-The purification of iodopsin was attempted with a view to determining its absorption spectrum. Baby chickens were decapitated, and the eyes removed. Crude digitalin extracts were prepared by slicing 12 to 24 eyes in half with a razor blade in dim red light, scooping out the retinas and adhering pigment layer into 2 per cent digitalin, extracting for 8 hours, and centrifuging clear. Such extracts contained large amounts of inert yellow impurities. These could be partly eliminated by soaking the half eyes in frog Ringer's solution for $1 \frac{1}{2}$ hours to split off the black pigment layer. Mammalian Ringer's did not have this action. Soaking was followed by hardening in $\mathrm{pH} 4.9$ acetate buffer for one-half hour. The retinas were then extracted 2 to 8 hours in $1.5 \mathrm{ml}$. of 2 per cent digitalin.

The ratio of iodopsin to rhodopsin was changed from $3 / 4$ to about 6 if the Ringer-soaked retinas were extracted $1 / 4$ to 2 hours with 4 per cent Merck's "pure" saponin in $3 / 4$ saturated magnesium sulfate, followed by filtration to separate the retinal residue. The yield of iodopsin was then about 50 per cent 
of that found in a crude extract. Unfortunately Merck's saponin became unavailable before a method of purification could be perfected. Several other brands of saponin, all of "purified" grade were tested, but proved far inferior in color and activity.

At best extracts made with magnesium sulfate possessed large amounts of impurities. Preliminary hardening with acetate could not be resorted to because such treatment rendered both iodopsin and rhodopsin insoluble.

(c) Dark Adaptation.-Scotopic dark adaptation, due to the regeneration of rhodopsin, is much slower than photopic. Since rhodopsin is a contaminant of iodopsin extracts, an attempt was made to eliminate rhodopsin by extracting retinas from light-adapted chicks after a minimum of dark adaptation.

This was accomplished by placing the chicks for about 15 minutes in a whitelined box with six 100 watt bulbs, removing the chicks individually to the dark, rapidly killing them, excising the eyes, and immersing them in 2 per cent digitalin. The total time in the dark to perform these operations was 2 to 3 minutes. After about 6 hours' extraction the collected retinas were centrifuged down and the extracted iodopsin and rhodopsin determined.

The ratio of iodopsin to rhodopsin was found to be substantially unchanged, and the total amount of each was about $3 / 4$ of the amount extracted from animals dark-adapted several hours. It is thus evident that regeneration of photopigments in the living chick was too rapid for differentiation among the component pigments.

(d) Distribution in the Retina.--Since cone vision is associated with high visual acuity, a faculty best developed in the retinal fovea, it seemed possible that extracts of the more central part of the retina might contain relatively less rhodopsin than the whole retina. An extract was therefore prepared from eyes sliced $1 / 4$ of the distance from the posterior pole instead of equatorially as usual. Inasmuch as the chicken retinal fovea is poorly developed it is not surprising that the foveal portion delivered the same proportion of rhodopsin to iodopsin as usual; i.e., 4:3.

(e) Extraction of Lizard Eyes.-The presence of rhodopsin in chicken eyes emphasized the desirability of using a pure cone eye as a source of iodopsin. The diurnal lizards approach this ideal much more closely than chickens.

Fifty retinas of the fence lizard, Sceloporus, from animals ranging in size between 6 and 10 inches long were extracted with $11 / 2 \mathrm{ml}$. of 2 per cent digitalin for 8 hours. No trace of photosensitivity could be detected in the extract.

Since the Sceloporus retinas were only about 0.1 the area of thick retinas, it was decided to try the night lizard, Xantusia. Although a nocturnal form, it contains no rhodopsin, relying on enormously enlarged cones for the necessary sensitivity in dim light (Walls, 1942). Eighteen eyes of a small species from the Mojave desert were extracted as above. On the basis of Walls' figures of retinal cross-sections about 10 times as much iodopsin would be ex- 
pected from the Xantusia extract; nevertheless the extract again contained no photopigments.

(f) Embryology.-It was of interest to investigate the stage of development at which iodopsin and rhodopsin appear, on the chance that they might be separated in this way.

The eyes of 6 chicks were removed at 12,16 , and $181 / 2$ days of incubation at $38-39^{\circ} \mathrm{C}$., extracted for 8 hours in $1 \frac{1}{2} \mathrm{cc}$. of 2 per cent digitalin, and tested for the presence of iodopsin and rhodopsin. Both substances were present in about equal quantity only in the $181 / 2$ day extraction. It thus is evident that visual substances are first formed on the 17th day of incubation.

\section{$V$. The Effectiveness of the Spectrum in Bleaching Iodopsin}

While a pure solution of iodopsin has not yet been obtained, a bleaching spectrum can be arrived at even with an impure solution because it is possible to correct for the effect of the impurities. We have seen that the bleaching effectiveness spectrum of rhodopsin resembles closely its absorption spectrum. In view of the similarities in the properties of iodopsin and rhodopsin this identity probably also holds for iodopsin. The relative bleaching effectiveness of light of various colors and known energy was therefore determined for dilute, 6 to 8 hour extracts of iodopsin prepared from acetate-hardened retinas as already described in the section on purification.

\section{(a) Apparatus.-}

Spectral bands were isolated with Corning and Wratten filter combinations. The bleaching light source for points above $450 \mathrm{~m} \mu$ was a 100 watt projection bulb run on a 110 volt A.c. voltage stabilizer and placed 6 inches from the $1 \mathrm{~cm}$. corex D cell. The color temperature of this light was determined by an Eastman meter to be $2800^{\circ} \mathrm{K}$. All filter combinations used with this source included a Bausch and Lomb heat-absorbing filter.

The bleaching source for points below $450 \mathrm{~m} \mu$ was a G. E. mercury arc lamp, type S4, run on 110 volts A.c. The mercury arc lines were isolated by Corning filters in combinations recommended by the manufacturers. A $1 \mathrm{~cm}$. layer of 5 per cent copper chloride solution was placed in the beam to remove the infrared spectrum of the mercury arc. The energy value of each line was determined with an 8 junction Hardy thermopile and a Leeds and Northrup HS galvanometer giving a sensitivity of 0.5 $\mu v . / \mathrm{mm}$. Deflections ranging from 2.4 to $25.0 \mathrm{~mm}$. were obtained.

\section{(b) Calculation of Filter Energy Transmission.-}

The transmission ratio $\left(E_{t r} / E_{0}\right)$ spectrum of each filter set in the projection bulb series was measured on Shlaer's spectrophotometer. The energy transmission $\left(\Sigma E_{t r}\right)$ of each filter set is equal to the value of the area under the curve of $E_{t r}$ plotted against wavelength. $\Sigma E_{t r}$ is arrived at by the multiplication of the filter transmission ratio $\left(E_{t r} / E_{0}\right)$ at each wavelength by the corresponding value of the energy distribution 
$\left(E_{o}\right)$ in the spectrum of a black body (Skogland, 1929) at the color temperature $\left(2800^{\circ} \mathrm{K}\right)$ of the bleaching source. The $E_{t_{r}}$ curves are shown in Fig. 4.

The center of gravity of the area $\left(\Sigma E_{t r}\right)$ under each of these curves was determined physically after the curves were cut out of cardboard; the wavelength of this point was used as the approximate equivalent wavelength of the spectral band transmitted by the filter combination. After the bleaching spectrum was obtained each energy curve was multiplied by the bleaching spectrum to obtain a center of gravity closer to the effective wavelength. This correction amounted to a few millimicrons at most in regions where the slope of the bleaching spectrum was steep. It expresses the fact that the most effective part of the filter band is that transmitting the greatest amount of energy absorbed by the photopigment.

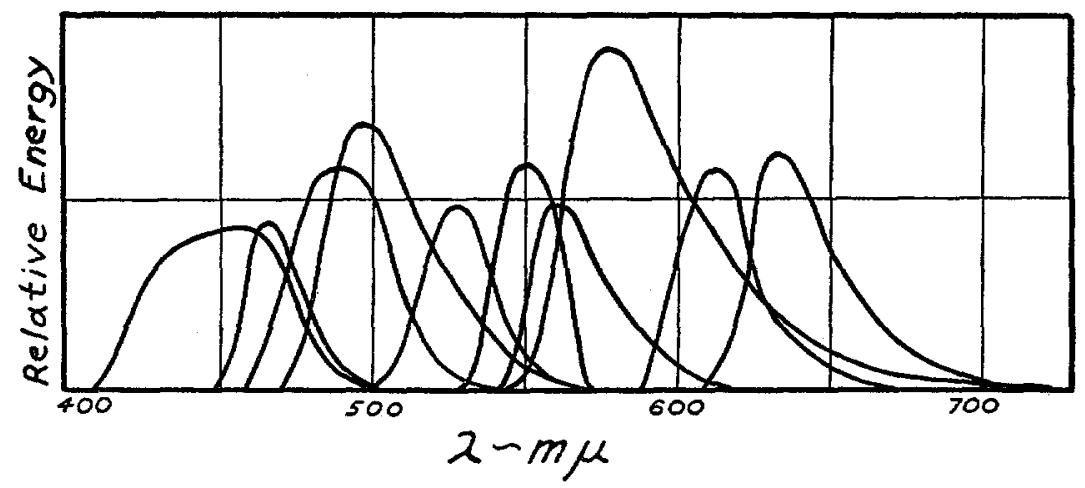

FIG. 4. Energy distribution of filter combinations given in Table 2. Ordinates of curves for filters with central wavelengths of $636,612,585$, and $450 \mathrm{~m} \mu$ are half the scale of the other curves.

Since the absorption of the solution itself contributes to the total filtering, the transmission at the wavelength of bleaching was measured at the end of each bleaching run. After correction for the absorption of the cell and water the value of the transmission at the center of the cell was computed and multiplied by the tranmission of the filter set to obtain the total effective energy. Except at 365 and $400 \mathrm{m \mu}$ the absorption of the cell and water could be ignored, since it changed less than 2 per cent about $400 \mathrm{~m} \mu$. Because the energies in the two series of wavelengths were determined independently the bleaching rates could not be directly compared. This relation was achieved by use of the fact that the rate at about $546 \mathrm{~m} \mu$ could be measured both in the mercury arc and the projection bulb series. The ratio for the rates found for the two sources at this wavelength was then used as a factor" to scale the mercury arc to the projection bulb series.

(c) Kinetics of Bleaching.-The bleaching course was followed at $615 \mathrm{~m} \mu$ since the maximum absorption fall due to simultaneously bleaching rhodopsin was only about 4 per cent of that due to iodopsin. A rough correction of the bleaching spectrum of iodopsin between 470 and $530 \mathrm{~m} \mu$ was made for this 
small effect in terms of the fact that rhodopsin was found to bleach about $11 / 2$ times as fast as iodopsin in green light with a dominant wavelength of $530 \mathrm{~m} \mu$.

Bleaching was found to be first order as in the case of rhodopsin (Hecht, 1920; Dartnall, Goodeve, and Lythgoe, 1936). This agrees with expectation for a photochemical reaction limited by light intensity. The integrated form of the first order equation assumes the following form in this case:

$$
k=\frac{\log a-\log x}{t},
$$

where $k$ is the bleaching factor, proportional to rate, $a$ is the original concentration of iodopsin, and $x$ is the concentration of iodopsin at time $t$. Expressed in terms of photometric density this becomes:

$$
k=\frac{\log \left(D_{\infty}-D_{\infty}\right)-\log \left(D_{t}-D_{\infty}\right)}{\ell} .
$$

where $D_{o}$ is the density before bleaching, $D_{t}$ is the density after bleaching for time $t$, and $D_{\infty}$ is the density after complete bleaching.

In the later stages of bleaching deviations from straightness usually appeared probably because of regeneration of iodopsin, which often reached 10 per cent of the original concentration. The regeneration was evident as a decrease in transmission on successive readings of the density. It gradually declined to zero in the course of several successive bleaches, each of sufficient intensity to cause full bleaching in about a minute. The methods found successful in stopping the regeneration of rhodopsin (addition of $\mathrm{pH} 11$ buffer and extraction with sodium desoxycholate) could not be used because they resulted in the destruction of iodopsin. A number of typical bleaching curves are shown in Fig. 5.

The effect of temperature on the bleaching of iodopsin must be considered. Hecht (1921) showed that the bleaching of rhodopsin, like other photochemical processes, was independent of temperature between 5 and $35^{\circ} \mathrm{C}$. Although it would be surprising to find iodopsin acting differently in this regard, the rate of bleaching of iodopsin in green light of $546 \mathrm{~m} \mu$ was measured not only at room temperature as usual, but also in one run at $5^{\circ}$. The rates differed by less than 10 per cent-well within the scatter of successive measurements of the bleaching rate under identical conditions.

In order to speed the measurement of the bleaching efficiency the slope of the straight line passing through the points of original and about half-concentration on the logarithmic bleaching curve was taken as the bleaching rate. This determination entailed the following measurements: density before bleaching, at the time of about half-bleaching, and at complete bleaching. At the end of the experiment another density reading was made at the wavelength of bleaching to obtain the self-filtering transmission of the solution. 
The density after bleaching was obtained as rapidly as possible to minimize the amount of regeneration during the readings. After the reading was roughly set the solution was again bleached in order to remove the iodopsin and rhodopsin forming during the preliminary reading.

(d) Light Intensity and Rate of Bleaching.-Before making the final calculation of bleaching effectiveness one further fact must be established-the linearity of the relation between rate of bleaching and incident energy. The nature of this relation was tested with the aid of the inverse square law.

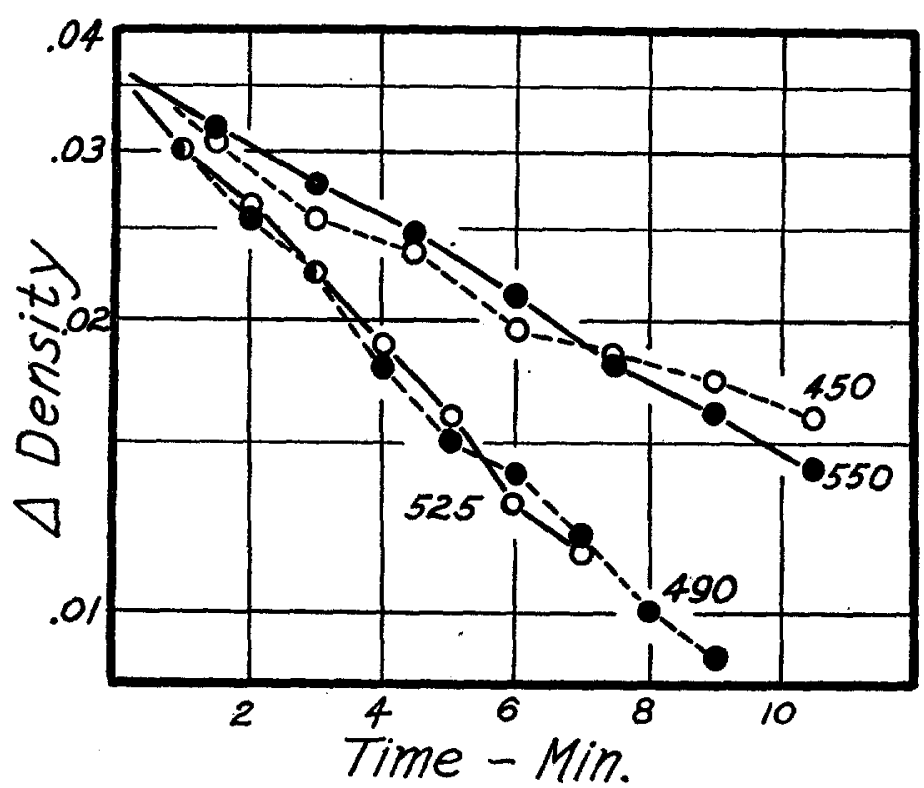

FIG. 5. Kinetics of bleaching of iodopsin with four parts of the spectrum. The density of the solution is measured at $615 \mathrm{~m} \mu$.

A 32 c.p. 6 volt automobile headlight, run at 5 volts A.c. was placed successively at 14.14 and $100 \mathrm{~cm}$. from the center of the cell and the rate of bleaching at the two distances compared. Under these conditions the half-times of bleaching fell within the range used for spectral bleaching; i.e., $1 / 2$ minute to $1 / 2$ hour.

A 2 per cent digitalin extract was prepared containing about 0.007 density per $\mathrm{cm}$. of iodopsin at $615 \mathrm{~m} \mu$. Samples of this extract were bleached about 50 per cent in times inversely proportional to the energy of the incident light. The bleaching effectiveness of the two energies was calculated from the following equation:

$$
\text { Bleaching effectiveness }=\frac{\log \left(D_{o}-D_{\infty}\right)-\log \left(D_{t}-D_{\infty}\right)}{(t) \text { (energy) (wavelength) }}
$$


The values actually obtained at the two relative energies are given in Table I. They show that the bleaching effectiveness is independent of the energy used

TABLE I

Light Intensity and Exposure in Bleaching of Iodopsin

\begin{tabular}{c|c|c|c|c}
\hline \multirow{2}{*}{ Relative energy } & Time & \multicolumn{3}{|c}{ Bleaching effectiveness } \\
& & 1 & 2 & Average \\
\hline & $\min$. & & & \\
0.5 & 25.0 & 0.0194 & 0.0179 & 0.0187 \\
25.0 & 0.5 & 0.0187 & 0.0187 & 0.0187 \\
\hline
\end{tabular}

TABLE II

Relative Effectiveness of Spectrum in Bleaching Iodopsin Projection Bulb Series

In filter combinations a number corresponds to a Corning glass of standard thickness unless followed by ( $\left.\frac{1}{2} \mathrm{~S}\right)$ which means half the standard thickness. A number preceded by (W) represents a Wratten filter from Eastman Kodak. A Bausch and Lomb heat-absorbing glass is designated by H.A.

\begin{tabular}{|c|c|c|c|c|c|c|c|c|c|c|}
\hline Filter combinations ... & $\begin{array}{l}5113(\mathrm{~S}) \\
3389 \\
\text { H.A. }\end{array}$ & $\begin{array}{l}5113\left(\begin{array}{l}1 \\
3387 \\
338(2)\end{array}\right) \\
\text { H.A. }\end{array}$ & $\begin{array}{l}\text { W)75 } \\
9780 \\
\text { H.A. }\end{array}$ & $\begin{array}{l}3385 \\
3387 \\
5030 \\
\text { H.A. }\end{array}$ & $\begin{array}{l}(W) 74 \\
4303(4) \\
3780 \\
\text { 378) } \\
\text { H.A. }\end{array}$ & $\begin{array}{l}3484 \\
4303 \\
5120 \\
\text { H.A. }\end{array}$ & $\begin{array}{l}4303 \\
3482 \\
\text { H.A. }\end{array}$ & $\begin{array}{l}3480 \\
4407 \\
\text { H.A. }\end{array}$ & $\begin{array}{l}2424 \\
4780 \\
\text { H.A. }\end{array}$ & $\begin{array}{l}2408 \\
\text { 9780(1 S) } \\
\text { H.A. }\end{array}$ \\
\hline 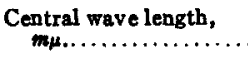 & 450 & 479 & 496 & 511 & 532 & 550 & 568 & 585 & 612 & 636 \\
\hline \multirow[t]{6}{*}{ Relative energy ......... } & 1440 & 372 & 465 & 1060 & 416 & 435 & 380 & 2694 & 1130 & 1300 \\
\hline & 20 & 23 & 44 & 58 & 79 & 91 & 99 & 63 & 41 & 15 \\
\hline & 16 & 22 & 43 & 57 & 79 & 90 & 96 & 63 & 37 & 14 \\
\hline & 16 & 22 & 42 & 56 & 77 & 90 & 89 & 60 & 36 & 14 \\
\hline & 15 & 22 & 40 & 52 & 73 & 90 & 85 & 59 & 33 & 14 \\
\hline & & 21 & 39 & 50 & 68.5 & 88 & 84 & 59 & 33 & \\
\hline Bleaching effec- & & & 38 & 50 & & 87 & 83 & 58 & 33 & \\
\hline tiveness.. & & & & & & $\begin{array}{l}86.5 \\
85\end{array}$ & & $\begin{array}{l}57 \\
55\end{array}$ & & \\
\hline & & & & & & 84.5 & & 55 & & \\
\hline & & & & & & 80 & & & & \\
\hline & & & & & & $\begin{array}{l}80 \\
79\end{array}$ & & & & \\
\hline & & & & & & 78 & & & & \\
\hline Average effective- & & & & & & & & & & \\
\hline ness. & 17 & 22 & 41 & 54 & 75 & 85 & 88 & 59 & 36 & 14 \\
\hline Quantum effective- & & & & & & & & & & \\
\hline ness. & 21 & 25 & 46 & 58 & 77 & 85 & 87 & 56 & 32 & 12 \\
\hline
\end{tabular}

for bleaching. The above equation can therefore be used to calculate the bleaching effectiveness of the spectrum if the energy at each wavelength is 
TABLE III

Relative Effectiveness of Spectrum in Bleaching Lodopsin Mercury Arc Series

\begin{tabular}{|c|c|c|c|c|}
\hline Corning filters ....... & $\begin{array}{l}738 \\
5860\end{array}$ & $\begin{array}{l}3060 \\
4308 \\
5970\end{array}$ & $\begin{array}{l}3389 \\
5113\end{array}$ & $\begin{array}{l}3484 \\
4303 \\
5120\end{array}$ \\
\hline Central wave length, $m \mu$. & 365 & 405 & 436 & 546 \\
\hline Relative energy...... & 6.9 & 3.7 & 22.9 & 9.1 \\
\hline \multirow{4}{*}{ Bleaching effectiveness. . } & 7.4 & 14.7 & 15.2 & 84 \\
\hline & 11.9 & 10.8 & 16.0 & 84 \\
\hline & 12.2 & 11.2 & 13.5 & 84 \\
\hline & 10.2 & 11.7 & 18.4 & 84 \\
\hline Average effectiveness........... & 10 & 12 & 16 & 84 \\
\hline Quantum effectiveness..... & 15 & 16 & 20 & 84 \\
\hline
\end{tabular}

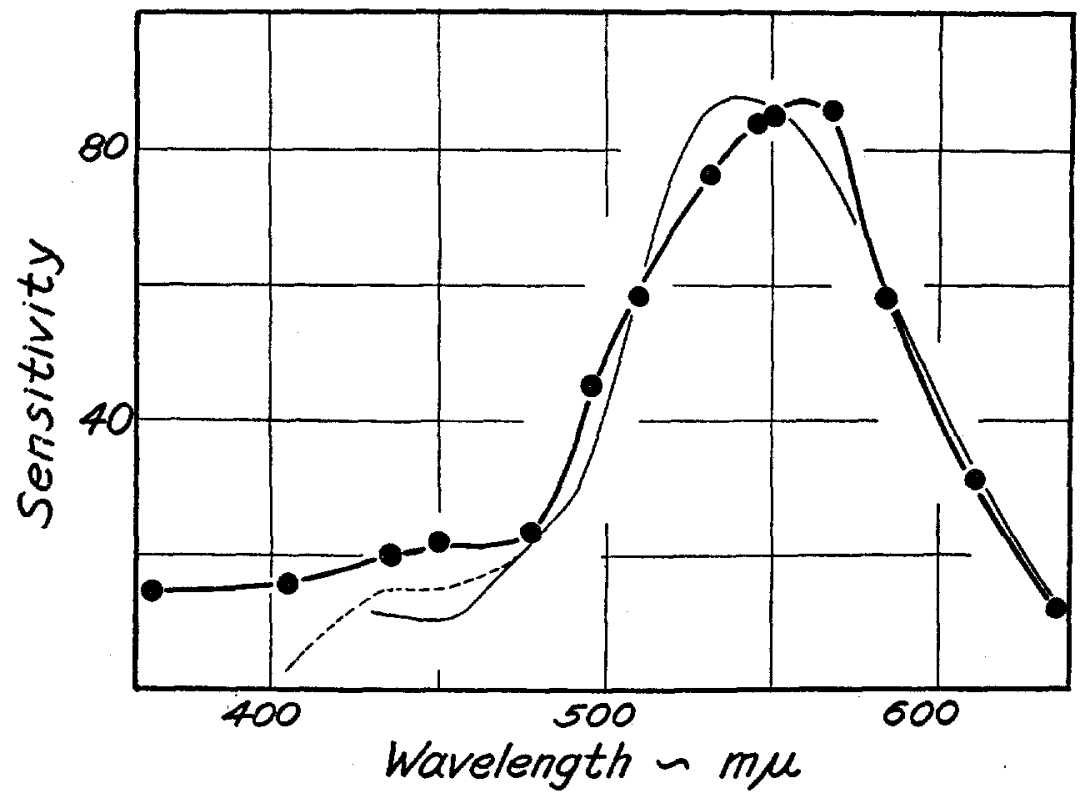

FIG. 6. Relation between spectrum luminosity and spectral sensitivity of iodopsin. Heavy line, spectral photosensitivity of iodopsin. Light line, spectral sensitivity of human cone vision according to Gibson and Tyndall (1923). Dotted line, according to Stiles (1944).

known. Introduction of the (wave length) term in this equation gives us the bleaching effectiveness in terms of quanta and thus makes possible a direct prediction of the corresponding absorption spectrum of iodopsin. 
(e) The Effectiveness Spectrum of Iodopsin and the Photopic Visibility Curve.The bleaching effectiveness of the spectrum was computed from the above equation. Because of the variations due to the cumulative effect of the sepa-

TABLE IV

Photopic Visibility Spectrum

Corrected for ocular and macular transmission and for quantum effect.

\begin{tabular}{|c|c|c|c|c|c|c|}
\hline $\begin{array}{l}\text { Wave } \\
\text { length }\end{array}$ & $\begin{array}{c}2 \\
\text { Gibson and } \\
\text { Tymdall } \\
\text { luminosity }\end{array}$ & $\begin{array}{c}3=2 / 1 \\
\text { Quantum } \\
\text { luminosity }\end{array}$ & $\begin{array}{c}4 \\
\text { Ocular } \\
\text { trans- } \\
\text { mission }\end{array}$ & $\begin{array}{c}5=3 / 4 \\
\text { Retinal } \\
\text { luminosity }\end{array}$ & $\underset{\substack{\text { Transmmission } \\
\text { of Macua }}}{6}$ & $\begin{array}{c}7=5 / 6 \\
\text { Cone } \\
\text { luminosity }\end{array}$ \\
\hline 400 & $0.5^{*}$ & 0.125 & 0.086 & 1.45 & 0.703 & 2.07 \\
\hline 10 & $1.2^{*}$ & 0.293 & 0.106 & 2.76 & 0.703 & 3.93 \\
\hline 20 & $2.2^{*}$ & 0.524 & 0.160 & 3.27 & 0.703 & 4.66 \\
\hline 30 & 3.3 & 0.767 & 0.248 & 3.09 & 0.703 & 4.40 \\
\hline 40 & 4.3 & 0.977 & 0.318 & 3.07 & 0.703 & 4.37 \\
\hline 50 & 5.1 & 1.13 & 0.388 & 2.92 & 0.705 & 4.14 \\
\hline 60 & 6.9 & 1.50 & 0.426 & 3.52 & 0.710 & 4.96 \\
\hline 70 & 10.3 & 2.19 & 0.438 & 5.00 & 0.718 & 6.97 \\
\hline 80 & 14.3 & 2.98 & 0.458 & 6.50 & 0.733 & 8.87 \\
\hline 90 & 19.6 & 4.00 & 0.481 & 8.31 & 0.751 & 11.07 \\
\hline 500 & 31.8 & 6.36 & 0.495 & 12.85 & 0.781 & 16.45 \\
\hline 10 & 52.3 & 10.25 & 0.511 & 20.07 & 0.834 & 24.06 \\
\hline 20 & 73.2 & 14.08 & 0.525 & 26.81 & 0.890 & 30.13 \\
\hline 30 & 87.8 & 16.57 & 0.542 & 30.56 & 0.924 & 33.08 \\
\hline 40 & 96.4 & 17.85 & 0.552 & 31.94 & 0.949 & 33.65 \\
\hline 50 & 99.8 & 18.14 & 0.567 & 32.00 & 0.966 & 33.13 \\
\hline 60 & 99.1 & 17.70 & 0.572 & 36.94 & 0.979 & 31.60 \\
\hline 70 & 94.7 & 16.61 & 0.583 & 28.50 & 0.990 & 28.78 \\
\hline 80 & 86.3 & 14.88 & 0.594 & 25.05 & 0.995 & 25.17 \\
\hline 90 & 75.4 & 12.78 & 0.602 & 21.23 & 1.000 & 21.23 \\
\hline 600 & 63.4 & 10.57 & 0.610 & 17.32 & 1.000 & 17.32 \\
\hline 10 & 51.1 & 8.38 & 0.621 & 13.49 & 1.000 & 13.49 \\
\hline 20 & 38.9 & 6.27 & 0.631 & 9.94 & 1.000 & 9.94 \\
\hline 30 & 27.9 & 4.43 & 0.640 & 6.92 & 1.000 & 6.92 \\
\hline 40 & 18.4 & 2.87 & 0.649 & 4.43 & 1.000 & 4.43 \\
\hline 50 & 11.3 & 1.74 & 0.658 & 2.64 & 1.000 & 2.64 \\
\hline 60 & 6.4 & 0.970 & 0.664 & 1.46 & 1.000 & 1.46 \\
\hline 70 & 3.5 & 0.522 & 0.677 & 0.771 & 1.000 & 0.771 \\
\hline 80 & 1.8 & 0.265 & 0.690 & 0.384 & 1.000 & 0.384 \\
\hline 90 & 0.9 & 0.130 & 0.696 & 0.187 & 1.000 & 0.187 \\
\hline 700 & 0.4 & 0.057 & 0.705 & 0.081 & 1.000 & 0.081 \\
\hline
\end{tabular}

* Extrapolated.

rate measurements involved in each determination of a bleaching effectiveness, values were obtained from several samples at each wavelength. The individual determinations are given in Table II and Table III, and the averages 
are plotted as the bleaching spectrum in Fig. 6. The sensitivity to light is seen to be greatest at $560 \mathrm{~m} \mu$.

In the same figure is the sensitivity of the human cones computed by Hecht (Table IV) from the original luminosity curve of Gibson and Tyndall (1923) corrected for quanta (Dartnall and Goodeve, 1937), for the absorption of the oscular media (Ludvigh and McCarthy, 1938), for the absorption of the macula lutea averaged from the data of Sachs (1891) and Kohlrausch (1931).

Since the values of luminosity below $430 \mathrm{~m} \mu$ in Gibson and Tyndall's curve are only roughly checked extrapolations, I have also computed the cone luminosity in the blue from a graph of the photopic visibility curve recently published by Stiles (1944). This is shown as the dotted line of Fig. 6 .

The fact that the light sensitivity of iodopsin differs only slightly from that of the human eye throughout nearly the whole visible spectrum is a strong indication of the similarity of iodopsin in the chick to the still unknown cone pigments of the human retina. The deviations, particularly the position of the maxima, may indicate a slight specific difference in the constitution of iodopsin, or the inadequacy of the correction for macular absorpt on, or a difference in the absorption spectrum of iodopsin attendant on solutiion with digitalin.

(f) Estimation of Yellow Impurities. - If we make the reasonable assumptions that the maximum heights of the difference spectra resulting from the bleaching of iodopsin and rhodopsin are approximately equal to the maximum absorptions of these substances, and if it is further assumed that the bleaching effectiveness spectrum of iodopsin is equal to its absorption spectrum, these absorption spectra may be added together and the result compared with the absorption of an actual extract. Perhaps 80 per cent of the absorption at $400 \mathrm{~m} \mu$ is thus found to be due to yellow impurities.

\section{Iodopsin and Color Vision}

Following the Young-Hemholtz trireceptor theory, one may assume that there are three types of cones in the human retina, each type containing a photosensitive pigment with an absorption spectrum slightly different from the other two (Hecht, 1934). An alternative theory, suggested particularly for the birds and reptiles, holds that the three types of receptors may be achieved by means of colored oil drop filters in the basal portion of the cones (Wald, 1937). However, Walls (1942) points out that the variable distribution of these drops in the retina indicates that their function is probably the reduction of chromatic aberration rather than color discrimination. Furthermore, Hamilton and Coleman (1933) have shown that the spectral hue discrimination curve of the pigeon is of nearly the same type as that of man, in whose cones oil droplets are lacking.

It would be interesting to test the homogeneity of iodopsin by partially 
bleaching it with red or blue light before determining the efficiency spectrum. If it is composed of several primary components, one of the primaries should bleach faster than the others, yielding an efficiency spectrum slightly different from that of the unbleached extract. Unfortunately the scatter of the determinations is too great to justify a search for the small differences to be expected from this treatment.

Weigert has attacked the problem of color vision from a different standpoint. $\mathrm{He}$ and his coworkers have shown that rhodopsin in thin gelatine films is photodichroic (Weigert and Morton, 1940). This is an expression of the fact that rhodopsin under these conditions bleaches maximally at the wavelength of the light with which it is bleached. He has suggested that rhodopsin is present in the cones in a similar physical state and therefore affords a mechanism for color discrimination.

However, it is difficult to reconcile such a mechanism with Müller's doctrine of nerve response. Furthermore, the discovery of iodopsin renders Weigert's hypothesis unnecessary.

\section{Phosphate Production and Illumination}

The photochemical bleaching of iodopsin and rhodopsin is only the first step in the visual process. Photoreception must be linked to the metabolic activity of the retina. Dittler's report (1907) of acid production by illuminated frog retinas was an early step in this direction. Later Lange and Simon (1922) showed a phosphate production by illuminated retinas. The frequency with which the work of these investigators is quoted makes desirable a reexamination of the retinal "phosphoric acid production" by modern methods.

(a) Acid Production. - The acid production was first investigated by Dittler's method. Each of a pair of Rana pipiens retinas, prepared in dim red light, was placed in a $0.5 \mathrm{cc}$. portion of an indicator solution containing $0.04 \mathrm{gm}$. $\mathrm{NaOH}$ and $0.016 \mathrm{gm}$. phenolphthalein per $500 \mathrm{cc}$. unbuffered Ringer's solution. One retina was illuminated with diffuse daylight; the other served as a dark control. The relative amount of fading of the indicator due to acid production by the retinas was observed after 10 to 20 minutes. The $\mathrm{pH}$ was then checked by the glass electrode.

Ten repetitions of this experiment showed only a random fluctuation of $0.2-$ $0.7 \mathrm{pH}$, evidently due to failure, as in Dittler's case, to wash the retinas free from tissue buffers.

The experiment was therefore repeated 5 times with retinas washed 1 hour in 5 to 10 changes of unbuffered Ringer's solution. The $\mathrm{pH}$ of such retinas remained constant within $0.2 \mathrm{pH}$, the limit of colorimetric error of Dittler's method. The positive results reported by Dittler thus probably were due to irregular diffusion of tissue buffers into the alkaline solutions he used.

(b) Inorganic Phosphate.-Inorganic phosphate production on illumination 
was next investigated, using the Küttner-Lichtenstein (1930) colorimetric method, entailing the reduction by $\mathrm{SnCl}_{2}$ of phosphomolybdic acid to blue molybdic oxides. A Bausch and Lomb Duboscq type microcolorimeter with a red filter was used, permitting the measurement of $0.0002 \mathrm{mg}$. $P$ from a $1 \mathrm{cc}$. sample with a variability of less than 5 per cent.

Retinas from two dark-adapted frogs were prepared in dim red light and a pair placed in each of two $1 \mathrm{cc}$. portions of P-free Ringer's solution which was changed 5 to 10 times in an hour to remove free phosphates. The solutions were then changed and their phosphate content determined at 30 minute intervals. One set of retinas remained in the dark throughout the experiment; the other remained in the dark for 30 minutes, after which it was illuminated by diffuse daylight for 30 minutes, and then replaced in the dark.

TABLE V

Phosphorus Release in Retina

Data are given as ratio of experimental to control retinas.

\begin{tabular}{|c|c|c|c|}
\hline Retina from frogs & 30 min. dark & $30 \mathrm{~min}$. light & 30 min. dark \\
\hline 2 pipiens & 0.9 & 1.1 & 1.0 \\
\hline 24 & 1.9 & 1.5 & 1.1 \\
\hline 24 & 1.3 & 1.1 & 1.1 \\
\hline $4 \quad 6$ & 1.4 & 1.1 & 1.0 \\
\hline " & 1.4 & 1.3 & 1.3 \\
\hline 1 bullfrog & 0.8 & 0.7 & 1.2 \\
\hline $2 "$ & 0.7 & 0.7 & 1.0 \\
\hline $1 "$ & 0.8 & 0.9 & 0.8 \\
\hline 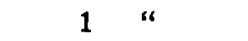 & 1.0 & 1.3 & 1.0 \\
\hline 1 " & 0.8 & 1.1 & 1.1 \\
\hline Average. . & 1.1 & 1.1 & 1.1 \\
\hline
\end{tabular}

The $\mathrm{P}$ content of such solutions ranged from 0.0002 to $0.0004 \mathrm{mg}$. In order to minimize the effects of individual variation and deterioration, the phosphate was expressed as ratio of phosphate produced by the illuminated retina to that of the control. Since individual differences in the ratios are large, the data of 10 experiments are presented in Table V. It is apparent that the present results agree with those of Wald, who has also been unable to confirm Lange and Simon's work. Wald (personal communication) says that his investigation of the balance of organic and inorganic phosphate fractions in the frog retina demonstrates no definite light effect. Lange and Simon give no details of their nephelometric method, so one is at a loss to discover the reason for their results.

The concept of light-induced phosphoric acid production has been accepted and extended by von Studnitz and his coworkers. Their measurements, 
however, cannot be accepted because of their failure to perform control experiments. Moreover, the data of Nover (von Studnitz, 1940) demonstrating the spectral sensitivity of retinal acid production are contradicted by those of Wigger (1937) showing the same change in the dark.

It is therefore concluded that there is as yet no convincing demonstration of a light-induced phosphoric acid release from the retina.

SUMMARY

1. While several reports of photosensitive pigments from the retinas of animals possessing large numbers of cone cells have been published, the only study which could be confirmed was Wald's discovery of iodopsin, a red-sensitive pigment from chicken eyes.

2. In its chemical properties, such as the range of $\mathrm{pH}$ stability and the effect of polar organic solvents, iodopsin resembles rhodopsin but is considerably more labile.

3. A partial purification from inert yellow impurities has been effected by prehardening the retinas in $\mathrm{pH} 4.9$ acetate buffer before extraction by 2 per cent digitonin. Rhodopsin was an inevitable contaminant in most methods of extraction, but could be reduced to about 10 per cent of the absorption due to iodopsin by extraction of unhardened retinas with 4 per cent Merck's saponin in $3 / 4$ saturated magnesium sulfate for about 1 hour.

4. The rate of bleaching of iodopsin was found to be first order and linear with respect to energy.

5. The bleaching effectiveness spectrum of iodopsin was determined with the aid of color filters of known energy transmission, and shows a maximum at $560 \mathrm{~m} \mu$ in the yellow green with a lower plateau in the blue. The spectrum is in good agreement with the sensitivity of the human cones except for the wavelength of maximum bleaching effectiveness. The maximum sensitivity of the human cones is found at $540 \mathrm{~m} \mu$.

6. Previous reports of changes in $\mathrm{pH}$ and inorganic phosphate level of retinas due to bleaching could not be confirmed.

I acknowledge with grateful appreciation the advice and constructive criticism of Professor Selig Hecht, at whose suggestion these problems were investigated, and of Dr. Simon Shlaer, who provided much guidance in spectrophotometric technics.

\section{BIBLIOGRAPHY}

Bliss, A. F., Derived photosensitive pigments from invertebrate eyes, J. Gen. Physiol., 1943, 26, 361.

Chase, A. M., and Haig, C., The absorption spectrum of visual purple, J. Gen. Physiol., $1938,21,411$.

Coblentz, W. W., and Emerson, W. B., Relative sensibility of the average eye to light of different colors and some practical applications to radiation problems, Bull. Bureau Standards, No. 303, 1918, 14, 167. 
Dartnall, H. J. A., and Goodeve, C. F., Scotopic luminosity curve and the absorption spectrum of visual purple, Nature, 1937, 139, 409.

Dartnall, H., Goodeve, C., and Lythgoe, R., The quantitative analysis of the photochemical bleaching of visual purple solutions in monochromatic light, Proc. Roy. Soc. London, Series A, 1936, 156, 158.

Dittler, H., Ueber die chemische Reaktion der isolierten Froschenetzhaut, Arch. ges. Physiol., 1907, 120, 120.

Fridericia, L., and Holm, E., The influence of deficiency of fat-soluble A-vitamin on the visual purple in the eyes of rats, Am.J. Physiol., 1925, 73, 63.

Gibson, K., and Tyndall, E., The visibility of radiant energy, Bureau Standards Scient. Papers, 1923, 19, 131.

Hamilton, W., and Coleman, T., Trichromatic vision in the pigeon as illustrated by the spectral hue discrimination curve, J. Comp. Psychol., 1933, 15, 183.

Hecht, S., Photochemistry of visual purple. I. The kinetics of the decomposition of visual purple by light, J. Gen. Physiol., 1920, 3, 1.

Hecht, S., Photochemistry of visual purple. II. The effect of temperature on the bleaching of visual purple by light, J. Gen. Physiol., 1921, 3, 285.

Hecht, S., The nature of the photoreceptor process, in A handbook of general experimental psychology, (C. Murchison, editor), Worcester, Clark University Press, 1934, 704.

Hecht, S., Rods, cones and the chemical basis of vision, Physiol. Rev., 1937, 17, 239.

Hecht, S., The chemistry of visual substances, Ann. Rev. Biochem., 1942, 11, 465.

Hecht, S., and Mandelbaum, J., Rod-cone dark adaptation and vitamin A, Science, 1938, 88, 219.

Hecht, S., Shlaer, S., and Pirenne, M., Energy, quanta, and vision, J. Gen Physiol., $1942,25,819$.

Hecht, S., and Williams, R., The visibility of monochromatic radiation and the absorption spectrum of visual purple, J. Gen. Physiol., 1922, 6, 1.

Holm, E., Demonstration of hemeralopia in rats nourished on food deficient in fatsoluble A-vitamin, Am.J. Physiol., 1925, 73, 79.

Honigman, H., Untersuchungen über die Lichtempfindlichkeit und Adaptierung des Vogelauges, Arch. ges. Physiol., 1921, 189, 1.

Hosoya, Y., Okita, T., and Akune, T., Ueber die lichtempfindliche Substanz in der Zapfennetzhaut, Tohoku J. Exp. Med., 1938, 34, 532.

Hunter, R., and Hawkins, E., Vitamin A aldehyde, Nature, 1944, 153, 194.

Hyde, E., Forsythe, W., and Cady, F., The visibility of radiation, Astrophysic. J., $1918,48,65$.

Ives, H., The spectral luminosity curve of the average eye, Phil. Mag., 1912, 6, 857.

Kohlrausch, A., Tagessehen, Dämmersehen, Adaptation, in Handbuch der normalen und pathologischen Physiologie, (A. Bethe, G. von Bergman, G. Embden, and A. Ellinger, editors), Berlin, Julius Springer, 1931, 12, pt. 2, Receptionsorgane 2 (Photoreceptoren 2).

Köttgen, E., and Abelsdorff, G., Absorption und Zersetzung des Sehpurpurs bei den Wirbeltieren, Z. Psychol. u. Physiol. Sinnesorgane, 1896, 12, 161.

Krause, A., and Sidwell, A., Absorption spectrum of visual purple and its photodecomposition products, Am. J. Physiol., 1938, 121, 215. 
Kuhne, W., Ueber den Sehpurpur, Untersuch. Physiol. Inst. Heidelberg, 1877, 1, 15.

Küttner, T., and Lichtenstein, L., Estimation of phosphorus, molybdic acid-stannous chloride reagent, J. Biol. Chem., 1930, 86, 671.

Lange, H., and Simon, M., Ueber Phosphorsäure Ausscheidung der Netzhaut bei Belichten, Z. physiol. Chem., 1922, 120, 1.

Ludvigh, E., and McCarthy, E., Absorption of the ocular media, Arch. Ophth., Chicago, 1938, 20, 37.

Lythgoe, R., Visual purple and indicator yellow, J. Physial., 1937, 89, 331.

Morton, R., and Goodwin, T., Preparation of retinene in vitro, Nature, 1944, 153, 405.

Penick, D., Direct current amplifier circuits for use with the electrometer tube, Rev. Scient. Instr., 1935, 6, 115.

Pinegin, N., Absolute photopic sensitivity of the eye in the ultraviolet and visible spectrum, Nature, 1944, 154, 770.

Sachs, M., Ueber die specifische Lichtabsorption des gelben Fleckes der Netzhaut, Arch. ges. Physiol., 1891, 50, 574.

Schneider, E., Goodeve, C., and Lythgoe, R., The spectral variation of the photosensitivity of visual purple, Proc. Roy. Soc. London, Series A, 1939, 170, 102.

Shlaer, S., A photoelectric transmission spectrophotometer for measurements of photosensitive solutions, J. Opt. Soc. America, 1937, 28, 18.

Skogland, J. Table of spectral energy distribution. Misc. Pub. Bureau Slandards No. 86, 1929; abridged in Smithsonian Physical Tables (F. E. Fowle), 1933, Washington, D. C., Smithsonian Institution.

Stiles, W., Current problems of visual research, Nature, 1944, 154, 290.

Von Studnitz, G., Weitere Studien an der Zapfensubstanz, Arch. ges. Physiol., 1937, 239, 515.

Von Studnitz, G., Physiologie des Sehens, Leipzig, Akademische Verlagsgesellschaft, 1940.

Tansley, K., The regeneration of visual purple, its relation to dark adaptation and night blindness, J. Physiol., 1931, 71, 442.

Wald, G., Carotenoids and the visual cycle, J. Gen. Physiol., 1935, 19, 351.

Wald, G., Photolabile substances of the chicken retina, Nature, 1937, 140, 545.

Wald, G., On rhodopsin in solution, J. Gen. Physiol., 1938, 21, 795.

Wald, G., The photoreceptor function of the carotenoids and vitamins A, vitamins and hormones, New York, Academic Press Inc., 1943.

Wald, G., Human vision and the spectrum, Science, 1945, 101, 653.

Walls, G., The vertebrate eye and its adaptive radiation, Cranbrook Inst. Sc., Bull. 19, Bloomfield Hills, Michigan, 1942.

Weigert, F., and Morton, N., Photochemical studies on colour vision, Ophthalmologica, $1940,99,145$.

Wigger, H., Versuche zur Kausalanalysse der retinomotorischen Erscheinungen, Arch. ges. Physiol., 1937, 239, 215. 